\title{
Possible link between Holocene East Asian monsoon and solar activity obtained from the EMD method
}

\author{
H. Y. Liu, Z. S. Lin, X. Z. Qi, Y. X. Li, M. T. Yu, H. Yang, and J. Shen \\ College of Geography Science, Nanjing Normal University, Nanjing, 210046, China
}

Correspondence to: Z. S. Lin (linzhenshan@njnu.edu.cn)

Received: 18 March 2010 - Revised: 6 July 2012 - Accepted: 10 July 2012 - Published: 10 August 2012

\begin{abstract}
It is thought that East Asian monsoon (EAM) is linked and sensitive to solar activity. In this paper, we have decomposed the Dongge cave speleothem $\delta^{18} \mathrm{O}$ record (proxy for EAM), and $\Delta^{14} \mathrm{C}$ and ${ }^{10} \mathrm{Be}$ (proxies for solar activity) time series into variations at different time scales with the empirical mode decomposition (EMD) method to reveal the possible link between the EAM variability and solar activity. There are some common cycles in the EAM and solar variability from centennial to millennial scales, indicating a possible link between EAM and solar activity at these time scales. The correlation between EAM and solar activity is much higher at millennial scales than at centennial scales, which means direct responses to the solar variation are more likely at time scales longer than a few hundred years. At $\sim 30,60$ and $600 \mathrm{yr}$ time scales, the variation in EAM is amplified by the solar amplitude modulation at $\sim 100,200$ and $2200 \mathrm{yr}$ time scales.
\end{abstract}

\section{Introduction}

The Holocene has long been regarded as an analog to the future of natural environment process, which began at the end of the Pleistocene (around $12000 \mathrm{yr} \mathrm{BP}$ ) and continues to the present. Detailed studies of Holocene climate change and the controlling mechanisms can provide a context for present and future global change, and increase our understanding of the underlying mechanisms of natural climate variability (Xue and Zhong, 2011). The East Asian monsoon (EAM) is an integral part of the global climatic system, which regulates global atmospheric circulation through heat and moisture transport from the warmest part of the tropical ocean, the west Pacific Warm Pool (WPWP), to higher latitudes (Wang et al., 2005), and plays a significant role in the socio-economic life of people in East Asia (Zong et al., 2006). Increasing evidence shows that there were abrupt changes and periodic fluctuations in East Asian monsoon on decadal to millennial scales during the Holocene (Sirocko et al., 1993; Hong et al., 2000; Gupta et al., 2003; Fleitmann et al., 2003). There are many factors affecting the East Asian monsoon, including orbitally induced insolation changes, changes in solar output, and changes in oceanic and atmospheric circulation (Wang et al., 2005). A number of existing high-resolution Holocene monsoon reconstructions from Indian and Asian monsoon domains, and some modelling studies, reveal an influence of solar variation on East Asian monsoon (Joussaume et al., 1999; Neff et al., 2001; Fleitmann et al., 2003; Gupta et al., 2003; Wang et al., 2005), which can be explained by a direct solar influence on the Intertropical Convergence Zone (ITCZ) that controls the monsoonal precipitation (Kodera, 2004). Asian monsoon is thought to be sensitive to relatively small changes in solar forcing $(0.25 \%$ change in solar output) (Neff et al., 2001; Fleitmann et al., 2003). The mechanism is not very clear (Cosford et al., 2008). It is suggested to be amplified by the Pacific Decadal Oscillation and El Niño-Southern Oscillation (ENSO) (Mann et al., 2005), and the North Atlantic Oscillation (Gimeno et al., 2003) or be due to the threshold effects (Dykoski et al., 2005).

Most of the previous studies explored the possible link between Asian monsoon and solar activity by direct comparisons among different proxy records (Hu et al., 2003; Gupta et al., 2003) or by the presence of some periodicities and coherence at certain bandwidths with respect to the ${ }^{14} \mathrm{C}$ and ${ }^{10} \mathrm{Be}$ data with spectral analysis (Dykoski et al., 2005; Xiao et al., 2006) and wavelet analysis (Witt and Schumann, 2005; Rousse et al., 2006; Cosford et al., 2008). Spectral analysis is a global analysis that gives the frequency components 
contained in the signal. It lacks the time localization of the spectral components. This type of analysis works best when the input signal is linear and stationary (Brigham, 1988; Qian, 2002). Short-time Fourier transform is able to capture the time-dependence of frequency fluctuations from nonstationary data. However, in order to localize an event precisely in time, the window width must be narrow. Alternately, the frequency resolution requires longer time spans. This leads to conflicting requirements (Heisenberg-Gabor inequality) and restrains this method from many practical applications (Barnhart and Eichinger, 2011). The wavelet analysis has been applied to diagnose climate changes. It has good ability to make multi-resolution analysis in both time domain and frequency domain. However, the choice of wavelet basis functions limits the applicability of the technique, as the basic functions of wavelet transformation are fixed and do not necessarily match the shape of the considered data series in every instant in time (Torrence and Compo, 1998).

A relative new time-frequency analysis method, designated empirical mode decomposition (EMD), has been proposed by Huang et al. (1998). The method essentially decomposes the original signal into a number of intrinsic mode function (IMF) components based on the local characteristic time scale of the signal and a residue. The EMD method is self-adaptive because the IMFs, working as the basis functions, are determined by the signal itself rather than what is pre-determined. Therefore, the EMD method is efficient in data analysis (Huang et al., 1998; Huang and Wu, 2007; Wu et al., 2007). In this paper, we will apply the EMD method to reveal the possible link between EAM and solar activity.

\section{EMD method and data source}

\subsection{EMD method}

According to the definition of the EMD method (Huang et al., 1998; Huang and Wu, 2007; Wu et al., 2007; Huang and Shen, 2005), the signal is decomposed into a finite number of IMFs, each of which represents a simple oscillatory mode and satisfies the following two conditions to ensure there are no riding waves (i.e. the wave motion formed by small-scale perturbation waves superposed on long-scale unperturbed waves): (1) in the whole dataset of the IMF, the number of extrema and the number of zero crossings must either be equal or differ at most by one; (2) at any point of the IMF, the mean value of the envelopes defined by the local maxima (relative maximum values that are greater than those values at the surrounding points), and local minima (relative minimum values that are smaller than those values at the surrounding points) is zero.

The decomposition method uses envelopes defined by the local maxima and the local minima of the original time series $X(t)$, respectively. Firstly, all local extrema are identified, and then all local maxima are connected by a cubic spline to form the upper envelope and minima are connected to form the lower envelope. Their mean is designated as $m_{11}(t)$, and the difference between $X(t)$ and $m_{11}(t)$ is the first component, $h_{11}(t)$, i.e.

$h_{11}(t)=X(t)-m_{11}(t)$.

However, $h_{11}(t)$ is still not stationary. So, the above process is repeated.

$h_{12}(t)=h_{11}(t)-m_{12}(t)$.

$m_{12}(t)$ is the mean envelope of $h_{11}(t)$.

Further iterations of this sifting process proceed until a standard deviation (SD) criterion is met. The SD is typically set between 0.2-0.3 (Huang et al., 1998).

$\mathrm{SD}=\sum_{t=0}^{T}\left[\frac{\mid\left(h_{1(i-1)}(t)-\left.h_{1 i}(t)\right|^{2}\right.}{h_{1(i-1)}^{2}(t)}\right]$

$T$ is the time length.

When SD criterion is satisfied after $k$ iterations, then

$h_{1 k}(t)=h_{1(k-1)}(t)-m_{1 k}(t)$.

The first IMF component $\left(c_{1}=h_{1 k}(t)\right)$ is separated from the rest of the data by

$r_{1}=X(t)-c_{1}$.

Since $r_{1}$ still contains information of longer period components, it is treated as the new data and subjected to the same sifting process as described above. The process is repeated and $r_{i}$ is described as follows:

$$
r_{1}=X(t)-c_{1}, r_{2}=r_{1}-c_{2}, \cdots, r_{n}=r_{n-1}-c_{n}
$$

i.e. $X(t)=\sum_{i=1}^{n} c_{i}+r_{n}$

or $X(t)=\sum_{i=1}^{n} \operatorname{IMF}_{i}(t)+r_{n}$

The sifting process can be stopped by any of the following predetermined criteria: either when the component, $c_{n}$, or the residue, $r_{n}$, becomes so small that it is less than the predetermined value of substantial consequence, or when the residue, $r_{n}$, becomes a monotonic function from which no more IMF can be extracted. Thus, we decompose $X(t)$ into $c_{i}=\operatorname{IMF}_{i}(t)$ with $i=1,2,3 \cdots, n$ and a residue, $r_{n}$, which can be either the mean trend or a constant.

To illustrate how the EMD method works, we consider a $1000 \mathrm{~s}$, three-frequency $\left(f_{1}=1 / 21, f_{2}=1 / 41\right.$ and $f_{3}=$ $1 / 100 \mathrm{~Hz}$ ) time series with Gaussian white noise $(G(t))$ as follows:

$$
\begin{aligned}
f(t) & =1.5 \times e^{\xi 2 \pi f_{1} t} \cos \left(2 \pi f_{1} t\right) \\
& +1.5 \times e^{-\xi 2 \pi f_{2} t} \cos \left(2 \pi f_{2} t\right)+2 \times \cos \left(2 \pi f_{3} t\right)+G(t)
\end{aligned}
$$



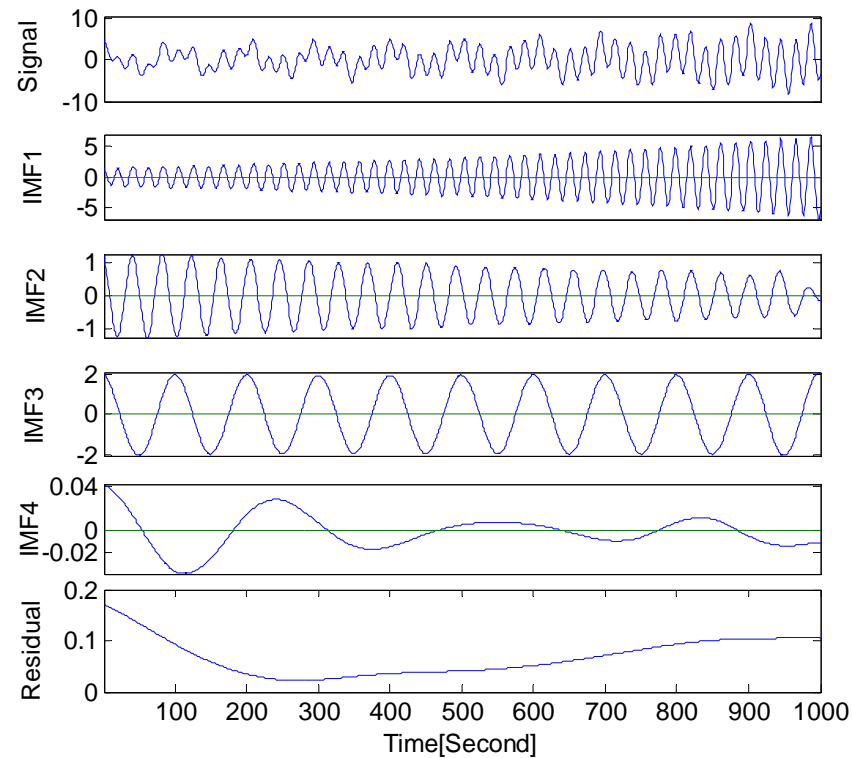

Fig. 1. Signal $f(t)=1.5 \times e^{\xi 2 \pi f_{1} t} \cos \left(2 \pi f_{1} t\right)+1.5 \times$ $e^{-\xi 2 \pi f_{2} t} \cos \left(2 \pi f_{2} t\right)+2 \times \cos \left(2 \pi f_{3} t\right)+G(t)$ and its decompositions using the EMD method. $\left(f_{1}=1 / 21, f_{2}=1 / 41\right.$, $f_{3}=1 / 100 \mathrm{~Hz}, \xi=0.01$ and the standard deviation of the mean-zero white noise is $10 \%$ of the signal strength).

where $\xi=0.01$ and the standard deviation of the mean-zero white noise is $10 \%$ of the signal strength.

The signal was decomposed into four IMF components and a residue with the EMD method (Fig. 1). The frequencies of the four IMF components are 1/21, 1/40.8, 1/99.7, and $1 / 280 \mathrm{~Hz}$ from high to low. The frequencies of IMF1, IMF2 and IMF3 are in good accord with the original three frequencies. The IMF4 and the residual may be mainly contributed by the Gaussian white noise. So, EMD method can decompose the original signal into a number of IMF components from high frequency to low frequency in order and adaptively.

Although the EMD method is powerful, one difficulty encountered when using EMD is the influence of the end point treatment. The envelopes are calculated using a cubic spline. However, splines are notoriously sensitive to end points. It is important to make sure that the end effects do not propagate into the interior solution (Lin and Wang, 2006).

\subsection{Data source}

Speleothems can have continuous deposition of calcium carbonate over long periods of time, and well-chosen speleothems are datable with high precision. Absolute ages can be determined by means of ${ }^{230} \mathrm{Th}$ dating by mass spectrometry (Dykoski et al., 2005; Cosford et al., 2008). Previous studies have shown that shifts in the oxygen isotope ratio $\left(\delta^{18} \mathrm{O}\right)$ of the stalagmite from the cave largely reflect changes in $\delta^{18} \mathrm{O}$ values of meteoric precipitation at the site,

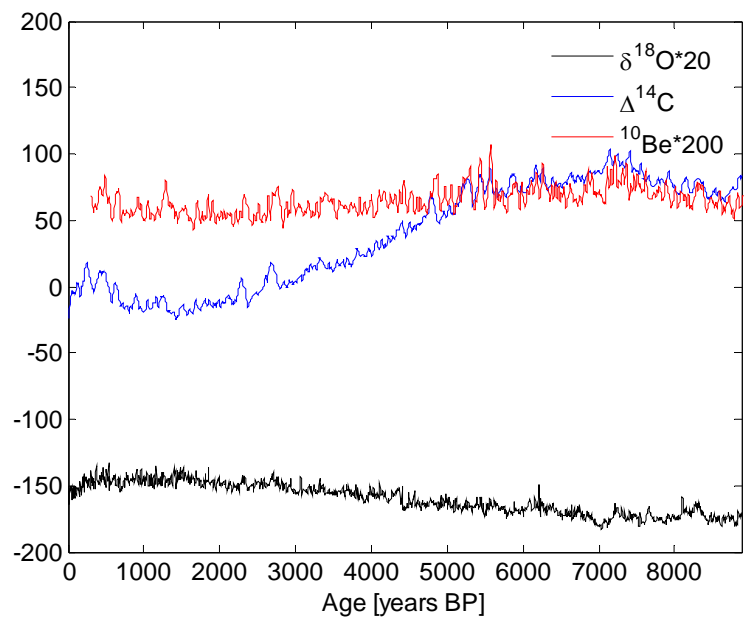

Fig. 2. Original signals of $\delta^{18} \mathrm{O}, \Delta{ }^{14} \mathrm{C}$ and ${ }^{10} \mathrm{Be}$ records.

which in turn relate to changes in the amount of precipitation and thus characterize the Asian monsoon strength (Dykoski et al., 2005). $\delta^{18} \mathrm{O}$ time series (from $9 \mathrm{kaBP}$ to the present; the present is defined as the year $1950 \mathrm{AD}$ ) of stalagmite $\mathrm{DA}$ from Dongge cave, southern China, with an average temporal resolution of 4-5 yr are used as a proxy of the high-resolution absolute-dated Holocene Asian monsoon record (Wang et al., 2005). Chronology of the 962.5 -mm-long stalagmite DA is established by $45^{230} \mathrm{Th}$ dates, all in stratigraphic order, with a typical age uncertainty of $50 \mathrm{yr}$ (Wang et al., 2005).

Owing to the lack of complete direct observations of the Sun for the period before $1600 \mathrm{AD}$, cosmogenic radionuclides ${ }^{14} \mathrm{C}$ (recorded in tree rings) and ${ }^{10} \mathrm{Be}$ (preserved in polar ice cores) are used as indirect proxies of solar variability (Yiou et al., 1997; Stuiver et al., 1998; Wagner et al., 2001; Muscheler et al., 2007). During the periods of lower sunspot activity, solar wind intensity is reduced, which increases the influx of galactic cosmic rays. A higher influx of cosmic rays increases the production of ${ }^{14} \mathrm{C}$ and ${ }^{10} \mathrm{Be}$ in the atmosphere. The reverse is true during the periods of increased sunspot activity when less ${ }^{14} \mathrm{C}$ and ${ }^{10} \mathrm{Be}$ are produced. Therefore, changes in atmospheric $\Delta^{14} \mathrm{C}$ and ${ }^{10} \mathrm{Be}$ can be related to changes in solar activity. In this paper, the tree-ring $\Delta^{14} \mathrm{C}$ record (from $9000 \mathrm{yr} \mathrm{BP}$ to the present) is from the IntCal04 calibration curve with 1-standard deviation envelope and data with 1-standard deviation error bars in ${ }^{14} \mathrm{C}$ and calibrated age (Reimer et al., 2004). The ${ }^{10} \mathrm{Be}$ record (from 304 to $9315 \mathrm{yr} \mathrm{BP}$ ) is from Greenland Ice Core Project (GRIP) ice core (Yiou et al., 1997; Wagner et al., 2001; Muscheler et al., 2007) with 5 yr temporal resolutions, and we use the timescale published by Johnsen et al. (1997) (ss09 timescale) by counting annual layers in the GRIP core.

The datasets of $\delta^{18} \mathrm{O}, \Delta{ }^{14} \mathrm{C}$ and ${ }^{10} \mathrm{Be}$ spaced at $10 \mathrm{yr}$ intervals (Fig. 2) are decomposed into signals at different time scales for further comparisons with the EMD method to 
reveal the possible link between solar activity and EAM intensity on different time scales.

\section{EMD analysis of $\delta^{18} \mathrm{O}, \Delta{ }^{14} \mathrm{C}$ and ${ }^{10} \mathrm{Be}$}

The EMD method was utilized to extract the intrinsic cycles of the datasets of $\delta^{18} \mathrm{O}, \Delta{ }^{14} \mathrm{C}$ and ${ }^{10} \mathrm{Be}$ (Fig. 3). The time series of $\delta^{18} \mathrm{O}$ was decomposed into seven IMF components and a residue, and the time series of ${ }^{10} \mathrm{Be}$ and $\Delta^{14} \mathrm{C}$ were decomposed into six IMF components and a residue respectively. The cycle of each IMF component is calculated using zero-crossing method.

The IMF components of $\delta^{18} \mathrm{O}$ correspond to decadal to millennial scale cycles centering on $31,65,118,234,600$, 1050 and $2000 \mathrm{yr}$ (Table 1), which are close to the cycles of 2040, 930, 568, 212, 120, 65 and $28 \mathrm{yr}$ in spectral analysis (Fig. 4a). In spectral analysis, multi-centennial to multimillennial cycles are stronger than multi-decadal cycles.

The cycles of the IMF components of $\Delta^{14} \mathrm{C}$ centre on 43 , $102,215,389,750,2291 \mathrm{yr}$. The cycles of 102, 215, 389 and $2291 \mathrm{yr}$ are close to $104,207,350$ and $2400 \mathrm{yr}$, which are strong in spectral analysis (Fig. 4b). These cycles are also revealed by previous studies (Stuiver and Braziunas, 1993; Ogurtsov et al., 2002). Although $\sim 750$ and $2291 \mathrm{yr}$ are not observed in the spectral analysis, $\sim 750 \mathrm{yr}$ cycle is reported in another study (Clemens, 2005), and $\sim 2291 \mathrm{yr}$ cycle is close to the Hallstatt cycle, which is revealed by Miller and Scott (1995) and Usoskin et al. (2009).

The cycles of the IMF components of ${ }^{10} \mathrm{Be}$ centre on 49 , $103,220,480,1005$ and $2200 \mathrm{yr}$, which is similar to the results of Yin et al. (2007). Cycles of 49, 103, 220 and $1005 \mathrm{yr}$ are also revealed in spectral analysis (Fig. 4c).

By the comparison of solar activity reconstructions from ${ }^{10} \mathrm{Be}$ GISP series and from $\Delta{ }^{14} \mathrm{C}$ series, Vonmoos et al. (2006) have shown that the agreement between them is good on centennial to millennial timescale. With the EMD method, the records of $\Delta{ }^{14} \mathrm{C}$ and ${ }^{10} \mathrm{Be}$ also show concurrent cycles on $\sim 100,200,1000$ and $2200 \mathrm{yr}$. The correlation coefficients on these scales are higher than on multi-decadal scales (Table 2). Although the cycle of IMF1 of $\Delta^{14} \mathrm{C}(44 \mathrm{yr})$ is close to that of ${ }^{10} \mathrm{Be}(49 \mathrm{yr})$, the correlation coefficient is very low (Table 2). Herein, good agreement between $\Delta^{14} \mathrm{C}$ and ${ }^{10} \mathrm{Be}$ on centennial to millennial timescale implies that the variations at these cycles are more likely caused by the solar modulation than at multi-decadal scales.

Although $\Delta^{14} \mathrm{C}$ and ${ }^{10} \mathrm{Be}$ are both used as proxy of solar activity, there are some discrepancies in their cycles. The cycle of IMF4 of $\Delta^{14} \mathrm{C}$ is $389 \mathrm{yr}$, while that of ${ }^{10} \mathrm{Be}$ is $480 \mathrm{yr}$. The $389 \mathrm{yr}$ cycle is close to a $360 \mathrm{yr}$ tidal cycle (Keeling and Whorf, 2000), and observed in a high-resolution $\delta^{18} \mathrm{O}$ record of peat cellulose in the Jilin Province in China (Hong et al., 2000), and in slope sediments of the Great Bahama Bank (Roth and Reijmer, 2005).The worldwide appearance of this signal thus points to the involvement of oceanic and

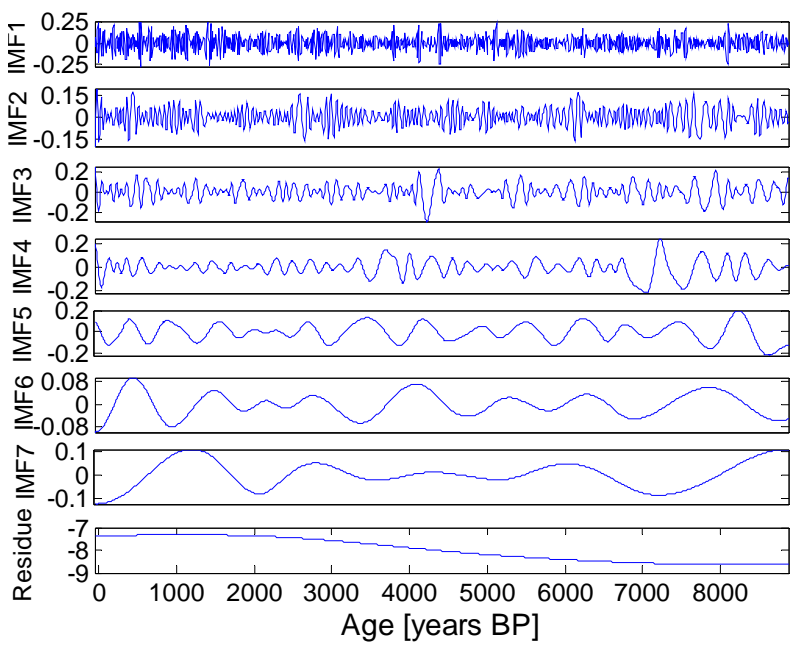

(a)

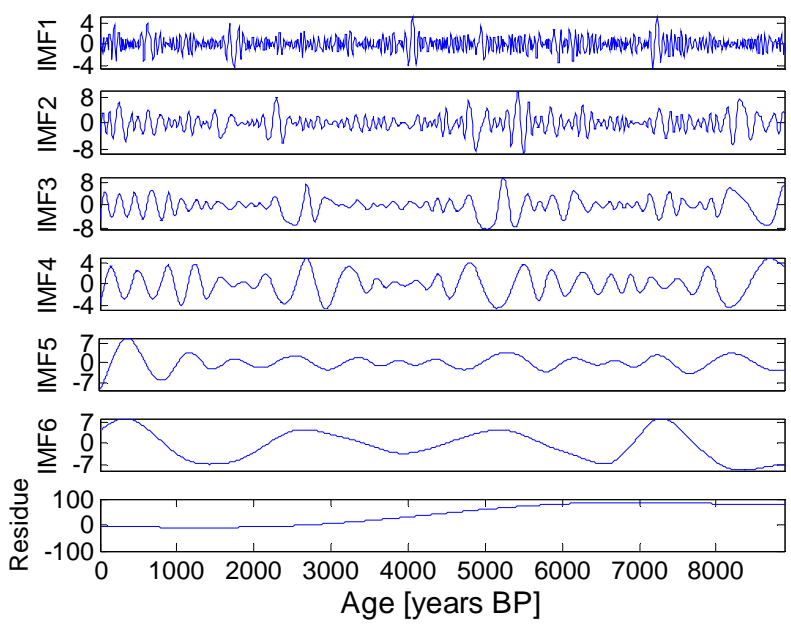

(b)

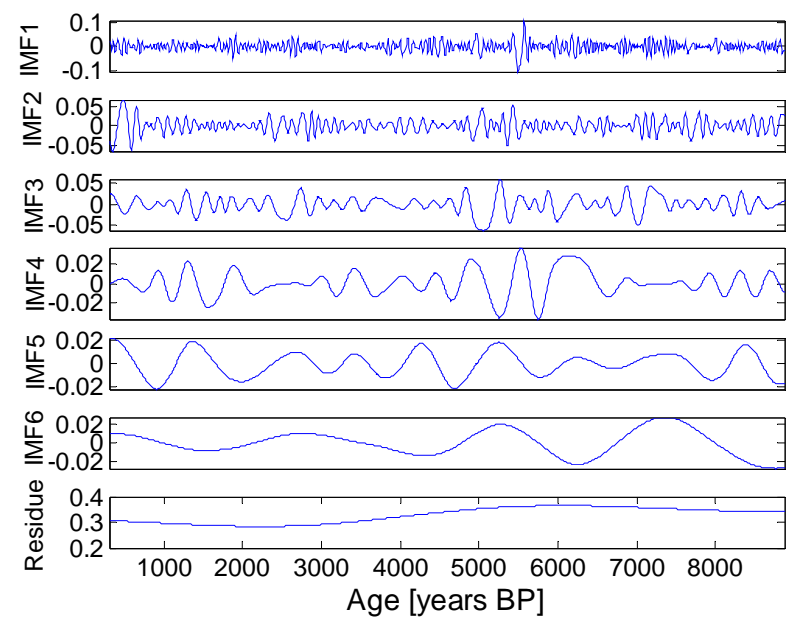

(c)

Fig. 3. EMD analysis of $\delta^{18} \mathrm{O}(\mathbf{a}), \Delta^{14} \mathrm{C}(\mathbf{b})$ and ${ }^{10} \mathrm{Be}(\mathbf{c})$ records. 
Table 1. Cycles of $\delta^{18} \mathrm{O}, \Delta^{14} \mathrm{C}$ and ${ }^{10} \mathrm{Be}$ with the EMD method.

\begin{tabular}{llrrrrrrr}
\hline & & IMF1 & IMF2 & IMF3 & IMF4 & IMF5 & IMF6 & IMF7 \\
\hline \multirow{2}{*}{${ }^{18} \mathrm{O}$} & cycles & 31 & 65 & 118 & 234 & 610 & 1050 & 2000 \\
& Std & 5.33 & 10.31 & 23.29 & 43.59 & 79.58 & 174.27 & 190.85 \\
\hline \multirow{2}{*}{$\Delta^{14} \mathrm{C}$} & cycles & 43 & 102 & 215 & 389 & 750 & 2291 & - \\
& Std & 18.15 & 40.94 & 100.42 & 106.32 & 184.84 & 220 & - \\
\hline \multirow{2}{*}{${ }^{10} \mathrm{Be}$} & cycles & 49 & 103 & 220 & 480 & 1005 & 2200 & - \\
& Std & 18.52 & 30.40 & 81.44 & 147.30 & 171.77 & 226.05 & - \\
\hline
\end{tabular}

Table 2. Correlation coefficients $(r)$ of IMFs between $\Delta^{14} \mathrm{C}$ and ${ }^{10} \mathrm{Be}$.

\begin{tabular}{lrrrrrr}
\hline Signal & IMF1 & IMF2 & IMF3 & IMF4 & IMF5 & IMF6 \\
\hline 0.6 & 0.0721 & 0.2305 & 0.4833 & 0.2447 & 0.5941 & 0.824 \\
\hline
\end{tabular}

large-scale atmospheric processes causing cyclicities with this frequency (Roth and Reijmer, 2005).The $\sim 500 \mathrm{yr}$ oscillation is thought to reflect a climatic process, involving thermohaline circulation and atmospheric processes that influenced atmospheric and oceanographic dynamics (Roth and Reijmer, 2005). Moreover, this cycle is possible to be a harmonic of the reported millennial-scale cycles or a subharmonic of the reported century-scale cycles.

Previous studies have pointed out that the short-term variations in ${ }^{10} \mathrm{Be}$ are mainly controlled by local climate (Muscheler et al., 2007; Usoskin et al., 2009). The EMD analysis shows that the amplitudes of ${ }^{10} \mathrm{Be}$ variation at short time scales are larger than those at long time scales (Fig. 3c). Moreover, the spectral analysis reveals there are many multidecadal cycles in ${ }^{10} \mathrm{Be}$ record (Fig. 4c). So, local climate may dominate the ${ }^{10} \mathrm{Be}$ data on short timescales as Usoskin et al. (2009) pointed out. Conversely, the amplitudes of shorttime variation in $\Delta^{14} \mathrm{C}$ are smaller than those of long-term variation (Fig. 3b), which is suggested to be due to the amplification of carbon cycle at long time scales by Muscheler et al. (2007).

\section{Relations between solar variability and East Asian monsoon at different time scales}

Most of the cycles found in Sect. 3 have been reported from mid to high northern latitudes (Bond et al., 2001; Hu et al., 2003) to low-latitude regimes (Fleitmann et al., 2003), including the Asian monsoon region (Wang et al., 2005; Xiao et al., 2006; Thamban et al., 2007). The cycles of $\sim 118$, 234, 1050 and $2000 \mathrm{yr}$ closely match those of $\Delta^{14} \mathrm{C}$ and ${ }^{10} \mathrm{Be}$. $\sim 118$ and $234 \mathrm{yr}$ cycles are close to $90 \mathrm{yr}$ (Gleissberg) and $207 \mathrm{yr}$ (Suess) solar cycles. The century-type cycle of Gleissberg has a wide frequency band with a double structure consisting of $50-80 \mathrm{yr}$ and $90-140 \mathrm{yr}$ periodicities, and the Suess cycle is less complex showing a variation with a period of 170-260 yr (Ogurtsov et al., 2002). These two cycles have been reported from East Asian monsoon (Dykoski et al., 2005; Xiao et al.,2006; Cosford et al., 2008), Indian monsoon (Neff et al., 2001; Agnihotri et al., 2002; Fleitmann et al., 2003; Thamban et al., 2007) and American monsoon (Asmerom et al., 2007; Stríkis et al., 2011) based on a variety of climate proxies. The $\sim 1000 \mathrm{yr}$ cycle is widely reported in stalagmites from Oman (Neff et al., 2001), sediments of the Arabian Sea (Thamban et al., 2007), peat cellulose from Hongyuan and Jinchuan (Xu et al., 2002) and lake sediments from Alaska (Hu et al., 2003). Its global nature due to the hemisphere-wide presence of this periodicity (Thamban et al., 2007) and its presence in ${ }^{10} \mathrm{Be}$ data support that it is related to the variations in solar activity. The $\sim 2000 \mathrm{yr}$ cycle was recorded in sediments of the Arabian Sea (Thamban et al., 2007) and Yangtze River-derived mud in the East China Sea (Xiao et al., 2006). The cycle was close to the $2560 \mathrm{yr}$ recorded in the Camp Century ice core $\delta^{18} \mathrm{O}$ profile (Dansgaard et al., 1984) and in the Okinawa Trough (Jian et al., 2000). The $\Delta{ }^{14} \mathrm{C}$ and ${ }^{10} \mathrm{Be}$ records both reveal $\sim 2200 \mathrm{yr}$ cycle, which is also revealed by other studies (Stuiver and Braziunas, 1993; Lean, 2002) and is close to Hallstattzeit cycle. Hence, $\sim 2200 \mathrm{yr}$ cycle may be linked to solar variability. Moreover, oceanic circulation is thought to play a significant role in transferring and modulating the variability at this time scale (Naidu and Malmgren, 1995; Thamban et al., 2007).

Although common cycles on $\sim 100,200,1000$ and $2000 \mathrm{yr}$ do not necessarily suggest a mechanistic link, they do indicate a possible link between the EAM and solar activity. As shown from Table 3, at millennial scales ( $\sim 1000$ and $2000 \mathrm{yr}$ ), the correlations between EAM and solar activity are much higher than at centennial scales, which means solar activity has greater influences on EAM at millennial scales.

The $\sim 30$ and $60 \mathrm{yr}$ cycles are very common in not only the modern but also secular monsoon records, including East Asian monsoon and India monsoon (Minobe, 1997; Agnihotri et al., 2002; Clemens, 2005; Dykoski et al., 2005; Wang et al., 2005; Mazzarella and Scafetta, 2012). However, both $\Delta{ }^{14} \mathrm{C}$ and ${ }^{10} \mathrm{Be}$ records do not reveal these two cycles with the EMD method. It seems there is no direct relation between 


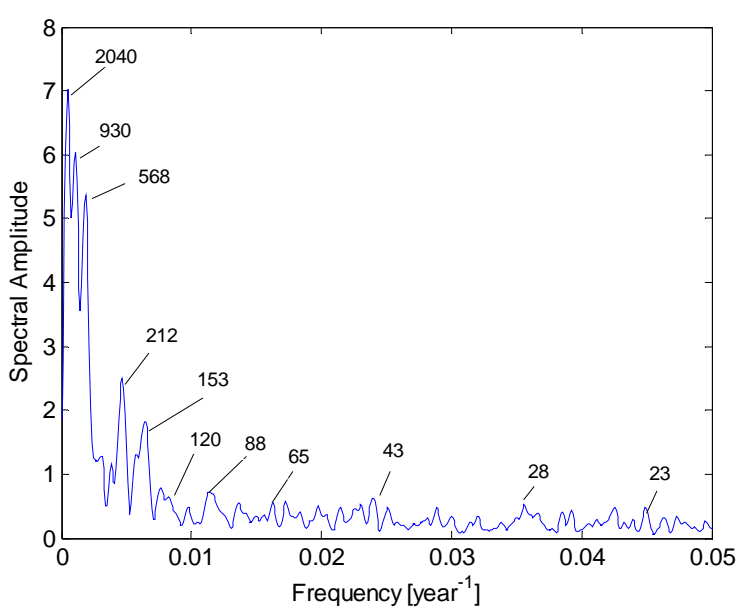

(a)

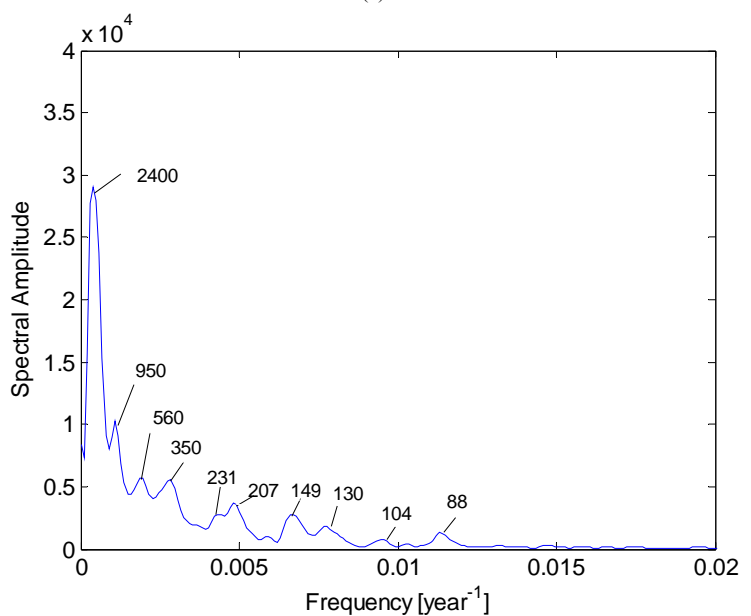

(b)

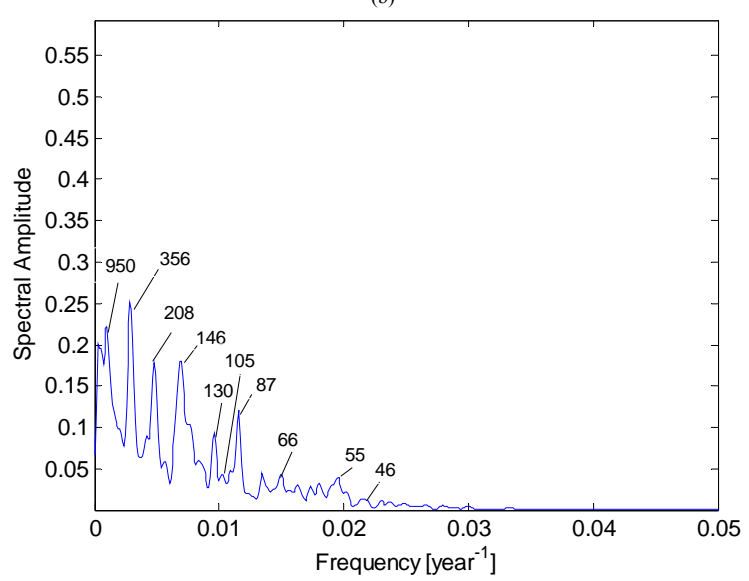

(c)

Fig. 4. Power spectrum using REDFIT3.6 (Schulz and Mudelsee, 2002) for $\delta^{18} \mathrm{O}(\mathbf{a}), \Delta^{14} \mathrm{C}(\mathbf{b})$ and ${ }^{10} \mathrm{Be}$ (c) records. Default parameters are used except that the parameter of $n 50$ representing the Welch's overlap segment averaging is 4 and Welch spectrum window is chosen (refer to Schulz and Mudelsee, 2002 for details).

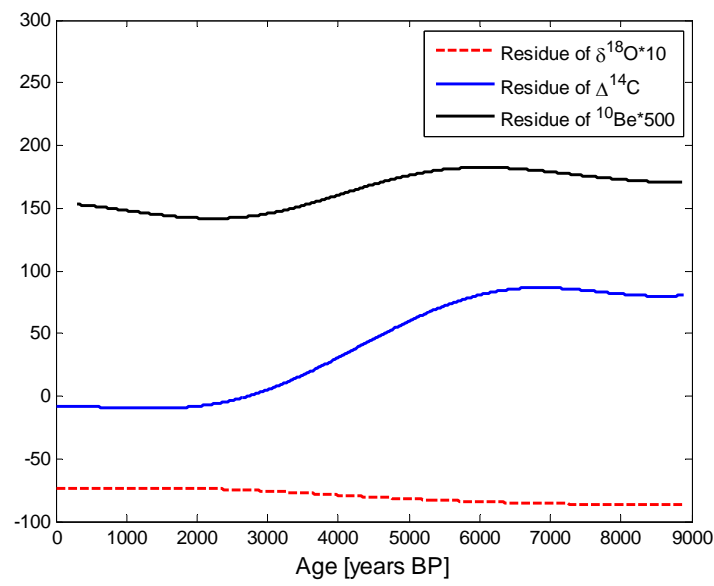

Fig. 5. Residues of $\delta^{18} \mathrm{O}(\mathbf{a}), \Delta^{14} \mathrm{C}$ (b) and ${ }^{10} \mathrm{Be}$ (c) records.

solar variability and EAM variation at multi-decadal time scales. However, the atmospheric pressure changes associated with the North Atlantic Ocean (NAO), and changes in sea-surface temperatures and thermohaline circulation associated with the Atlantic Multidecadal Oscillation (AMO) exhibit a $\sim 60 \mathrm{yr}$ cycle (Schlesinger and Ramakutty, 1994; Kerr, 2000; Gimeno et al., 2003; Knudsen et al., 2011). Moreover, the Pacific Decadal Oscillation (PDO) resembles the well-known ENSO system, but operates in the North Pacific and exhibits 25-35 yr and 50-70 yr cycles (Minobe, 1997). So, $\sim 30$ and $60 \mathrm{yr}$ cycles are thought to be linked to the Pacific Decadal Oscillation and the North Atlantic Oscillation (Schlesinger and Ramankuty, 1994; Gimeno et al., 2003; Knudsen et al., 2011; Mazzarella and Scafetta, 2012). $\sim 600 \mathrm{yr}$ cycle is revealed in the Lianhua A1, Heshang HS4, Dongge DA and D4 speleothem $\delta^{18} \mathrm{O}$ records (Cosford et al., 2008). It is close to the prominent $649 \mathrm{yr}$ cycle discovered by Damon and Sonett (1991) and is thought to be related to solar variability (Zhu et al., 2009). However, this cycle is not observed in $\Delta{ }^{14} \mathrm{C}$ and ${ }^{10} \mathrm{Be}$ records with the EMD method. Hence, it seems that solar variability has few or indirect influence on EAM at this time scale.

The residues of $\delta^{18} \mathrm{O}, \Delta{ }^{14} \mathrm{C}$ and ${ }^{10} \mathrm{Be}$ have been compared to show their long-term trends (Fig. 5). The residue of $\delta^{18} \mathrm{O}$ increased gradually, which means the Asian monsoon weakened through the Holocene. It is thought to be caused by the gradual decrease in summer insolation (Overpeck et al., 1996). The long-term trend of $\delta^{18} \mathrm{O}$ is quite different from that of $\Delta^{14} \mathrm{C}$ and ${ }^{10} \mathrm{Be}$, which means that different driving forces control them. It is because the radionuclide production rates on long time scales (> $3000 \mathrm{yr}$ ) are probably caused by geomagnetic modulation and those on short time scales $(<3000 \mathrm{yr})$ are most likely of solar origin (Beer, 2000).There is a slight discrepancy between the long-term trend of $\Delta^{14} \mathrm{C}$ and ${ }^{10} \mathrm{Be}$. Whether this discrepancy is mainly due to changes in the $\Delta^{14} \mathrm{C}$ or the ${ }^{10} \mathrm{Be}$ system cannot yet be decided without further information (Vonmoos et al., 2006; Muscheler et al., 2007). 
Table 3. Correlation coefficients $(r) \delta^{18} \mathrm{O}$ with $\Delta^{14} \mathrm{C}$ and ${ }^{10} \mathrm{Be}$ at $\sim$ 100, 200, 1000 and 2000-yr time scales.

\begin{tabular}{lrrrr}
\hline $\begin{array}{l}\delta^{18} \text { O Correlation } \\
\text { coefficients }(r)\end{array}$ & $\sim 100$ & $\sim 200$ & $\sim 1000$ & $\sim 2000$ \\
\hline$\Delta^{14} \mathrm{C}$ & 0.23 & -0.0161 & 0.2944 & -0.5551 \\
${ }^{10} \mathrm{Be}$ & 0.1145 & 0.2385 & 0.4298 & -0.6096 \\
\hline
\end{tabular}

\section{Possible solar modulation of East Asian monsoon}

Both radionuclides exhibit the same solar signal despite the fact that different conditions influenced their concentrations before their deposition in the archives (Vonmoos et al., 2006). However, ${ }^{10} \mathrm{Be}$ has a better correlation with $\delta^{18} \mathrm{O}$ than $\Delta^{14} \mathrm{C}$ (Table 3). Especially, at $\sim 200 \mathrm{yr}$ time scale, correlation coefficient between $\Delta^{14} \mathrm{C}$ and $\delta^{18} \mathrm{O}$ is very low $(r=-0.0161)$, while that between ${ }^{10} \mathrm{Be}$ and $\delta^{18} \mathrm{O}$ is remarkable $(r=0.2385)$. It seems that there is almost no correlation between $\Delta^{14} \mathrm{C}$ and $\delta^{18} \mathrm{O}$ at this time scale. Therefore, ${ }^{10} \mathrm{Be}$ is used as a proxy of solar activity for further comparison with $\delta^{18} \mathrm{O}$ in this article.

$\sim 30,60$ and $600 \mathrm{yr}$ cycles are absent in ${ }^{10} \mathrm{Be}$ and $\Delta^{14} \mathrm{C}$ records with the EMD method. Although these cycles are observed in the spectral analysis in other studies (Neff et al., 2001; Fleitmann et al., 2003), they are too small to cause significant impact on the climate of the Earth. So, these three time scales are thought to be indirectly affected by solar variability through the interaction between atmospheric and ocean circulation that amplify this initial signal (Neff et al., 2001). With the EMD method, the amplitudes of these three IMFs of EAM change with time and, in fact, have characteristics of slowly varying wavelet packets (Fig. 4). So, there are possible amplitude modulations of EAM by some driving forces at these time scales. The envelope of an IMF is symmetric, so it is only necessary to examine the maximum values in order to identify the characteristics of this cycle (Lin and Wang, 2003). To reveal possible solar modulation of EAM, the envelopes of IMF1, IMF2 and IMF5 of $\delta^{18} \mathrm{O}$ have been compared with IMF2, IMF3 and IMF6 of ${ }^{10} \mathrm{Be}$ respectively (Fig. 6). The crests of the envelope of the IMF1 of $\delta^{18} \mathrm{O}$ largely coincide with the troughs of the IMF 2 of ${ }^{10} \mathrm{Be}$ and vice versa (Fig. 6a), which means there is an inverse phase relation between them. Similarly, the envelopes of IMF2 and IMF5 of $\delta^{18} \mathrm{O}$ are also in inverse phase with the IMF3 and IMF6 of ${ }^{10} \mathrm{Be}$ in great part. So, $\sim 100,200,2000 \mathrm{yr}$ solar variability are adaptations to $\sim 30,60$ and $600 \mathrm{yr}$ EAM variation, and EAM variation is amplitude modulated by solar variation.

The $\sim 200 \mathrm{yr}$ Suess cycle and $2200 \mathrm{yr}$ Hallstattzeit cycle are thought to modulate the century-type cycle of Gleissberg, and the century-type cycle of Gleissberg is thought to modulate the $11 \mathrm{yr}$ Schwabe cycle (Peristykh and Damon, 2003). In this article, $\sim 100,200$ and $2200 \mathrm{yr}$ solar variations

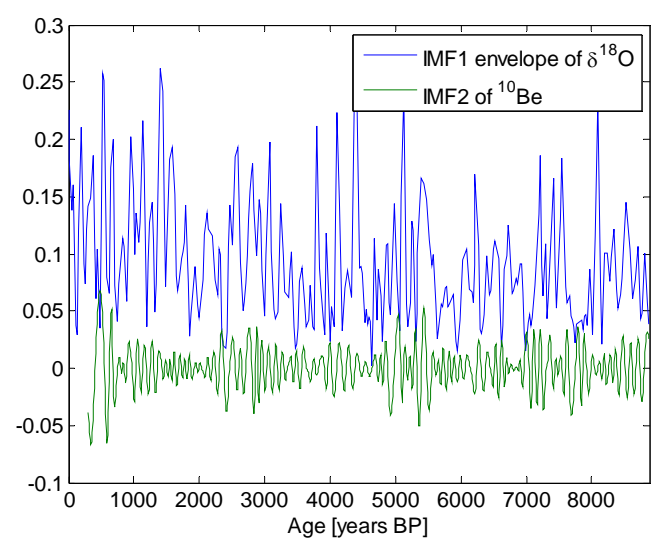

(a)

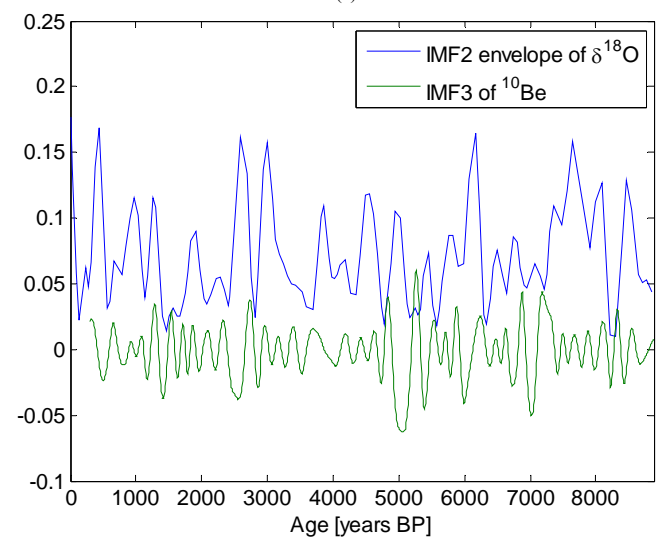

(b)

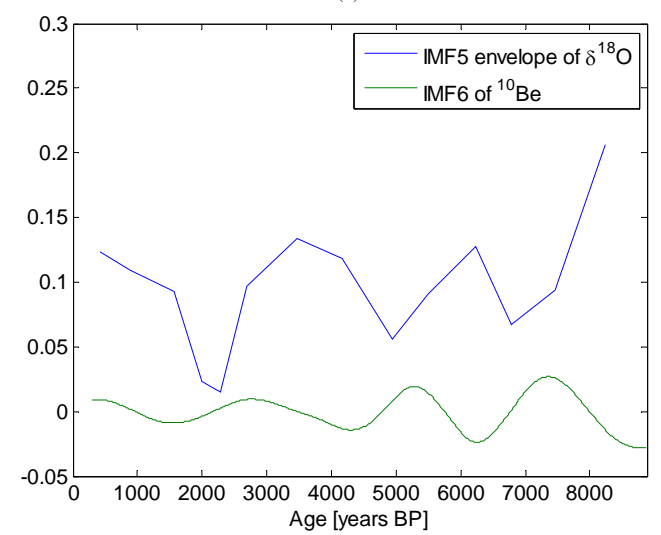

(c)

Fig. 6. Comparisons between the envelopes of IMFs of $\delta^{18} \mathrm{O}$ and IMFs of ${ }^{10} \mathrm{Be}$. (a) IMF1 envelope of $\delta^{18} \mathrm{O}$ and IMF2 of ${ }^{10} \mathrm{Be}$. (b) IMF2 envelope of $1 \delta^{18} \mathrm{O}$ and IMF3 of ${ }^{10} \mathrm{Be}$. (c) IMF5 envelope of $\delta^{18} \mathrm{O}$ and IMF6 of ${ }^{10} \mathrm{Be}$.

are also thought to modulate EAM variations at $\sim 30,60$ and $600 \mathrm{yr}$, respectively. Moreover, solar variations at $\sim 100$, $200,2000 \mathrm{yr}$ time scales are as large as at the other time scales in both spectral and EMD analysis. So, the changes in solar variation at these three time scales may amplify the changes in EAM at 30,60 and $600 \mathrm{yr}$ time scales. By this way, small changes in solar activity at 30,60 and $600 \mathrm{yr}$ may 
be able to trigger larger changes in EAM. Therefore, solar variability may be a plausible direct driver of EAM at these three time scales.

\section{Conclusions}

EAM and solar activity share some common cycles on $\sim 100,200,1000$ and $2000 \mathrm{yr}$ time scales. This supports the idea that solar changes are partly responsible for changes in Holocene EAM intensity from centennial to millennial scales (Dykoski et al., 2005; Wang et al., 2005; Cosford et al., 2008). Moreover, EAM and solar activity have much higher correlation at millennial time scales than at centennial time scales. This result also supports the assumption that a direct response to the solar variation holds more likely for time scales longer than a few hundred years (Weber et al., 2004).

The ${ }^{10} \mathrm{Be}$ and $\Delta^{14} \mathrm{C}$ records do not reveal cycles at $\sim 30,60$ and $600 \mathrm{yr}$, and, hence, it seems that there is no direct relation between EAM and solar activity at these time scales. However, EAM intensity at these time scales is amplitude modulated by solar activities at $\sim 100,220$, and $2200 \mathrm{yr}$, which implies that solar activity is a plausible driver of EAM at these time scales. So, EAM variation at $~ 30,60$ and $600 \mathrm{yr}$ time scales may be directly amplified by solar activity. It may be a possible mechanism to explain why small changes in solar output at these time scales can cause large changes in EAM.

Acknowledgements. This research has been supported by China NSF (No. 41173093, 40901094, 41030751), and funded by the Priority Academic Program Development of Jiangsu Higher Education Institutions and Jiangsu Oversea Research and Training Program for University Prominent Young and Middle-aged teachers and Presidents. We also thank the anonymous reviewers for helpful suggestions.

Edited by: J. Kurths

Reviewed by: two anonymous referees

\section{References}

Agnihotri, R., Dutta, K., Bhushan, R., and Somayajulu, B.: Evidence for solar forcing on the Indian monsoon during the last millennium, Earth. Planet. Sci. Lett., 198, 521-527, 2002.

Asmerom, Y., Polyak, V., Burns, S., and Rasmussen, J.: Solar forcing of Holocene climate: New insights from a speleothem record, southwestern United States, Geology, 35, 1-4, 2007.

Barnhart, B. L. and Eichinger, W. E.: Empirical Mode Decomposition Applied to Solar Irradiance, Global Temperature, Sunspot Number, and $\mathrm{CO}_{2}$ Concentration Data, J. Atmos. Solar. Terr. Phys., 73, 1771-1779, 2011.

Beer, J.: Long-term indirect indices of solar variability, Space. Sci. Rev., 94, 53-66, 2000.

Bond, G., Kromer, B., Beer, J., Muscheler, R., Evans, M. N., Showers, W., Hoffmann, S., Lotti-Bond, R., Hajdas, I., and Bonani,
G.: Persistent solar influence on North Atlantic Climate during the Holocene, Science, 294, 30-36, 2001.

Brigham, E.: The Fast Fourier Transform and its Applications, Prentice Hall, Englewood Cliffs, NJ, 1988.

Cosford, J., Qing, H., Eglington, B., Yuan, D. X., Zhang, M. L., and Chen, H.: East Asian monsoon variability since the MidHolocene recorded in a high-resolution, absolute-dated aragonite speleothem from eastern China, Earth. Planet. Sci. Lett., 275, 296-307, 2008.

Clemens, S. C.: Millennial-band climate spectrum resolved and linked to centennial-scale solar cycles, Quaternary Sci. Rev., 24, 521-531, 2005.

Damon, P. E. and Sonett, C. P.: Solar and terrestrial components of the atmospheric ${ }^{14} \mathrm{C}$ variation spectrum, in: The Sun in Time, edited by: Sonett, C. P., Giampapa, M. S., and Matthews, M. S., Univ. of Ariz. Press, Tucson, 360-388, 1991.

Dansgaard, W., Johnsen, S. J., Clausen, H. B., Dahl-Jensen, N., Gundestrup, N., and Hammer, C. U.: North Atlantic climatic oscillations revealed by deep Greenland ice cores, in Climate Processes and Climate Sensitivity, Geophys. Monogr. Ser., 29, 288298, 1984.

Dykoski, C. A., Edwardsa, R. L., Cheng, H., Yuan, D. X., Cai, Y. J., Zhang, M. L., Lin, Y. S., Qin, J. M., and An, Z. S.: A high resolution, absolute-dated Holocene and deglacial Asian monsoon record from Dongge Cave, China, Earth. Planet. Sci. Lett., 233, 71-86, 2005.

Fleitmann, D., Burns, S. J., Mudelsee, M., Neff, U., Kramers, J., Mangini, A., and Matter, A.: Holocene forcing of the Indian monsoon recorded in a stalagmite from Southern Oman, Science, 300, 1737-1739, 2003.

Gupta, A. K., Anderson, D. M., and Overpeck, J. T.: Abrupt changes in the Asian southwest monsoon during the Holocene and their links to the North Atlantic Ocean, Science, 42, 354-357, 2003.

Gimeno, L., de la Torre, L., Nieto, R., Garcia, R., Hernandez, E., and Ribera, P.: Changes in the relationship NAO-Northern Hemisphere temperature due to solar activity, Earth. Planet. Sci. Lett., 206, 15-20, 2003.

Hu, F. S., Kaufman, D., Yoneji, S., Nelson, D., Shemesh, A., Huang, Y., Tian, J., Bond, G., Clegg, B., and Brown, T.: Cyclic variation and solar forcing of Holocene climate in the Alaskan subarctic, Science, 301, 1890-1893, 2003.

Huang, N. E., Shen, Z., and Long, S. R.: The empirical mode decomposition and the Hilbert spectrum for nonlinear and nonstationary time series analysis, Proc. R. Soc. Land. A., 454, 899955, 1998.

Huang, N. E. and Wu, Z.: A review on hilbert-huang transform: method and its applications to geophysical studies, Rev. Geophys., 46, RG2006, doi:10.1029/2007RG000228, 2007.

Huang, N. E. and Shen, S. L.: Hilbert-Huang transform and its applications, World Scientific Press, Singapore, 2005.

Hong, Y. T., Jiang, H. B., Liu, T. S., Zhou, L. P., Beer, J., Li, H. D., Leng, X. T., Hong, B., and Qin, X. G.: Response of climate to solar forcing recorded in a 6000 -year $\delta^{18} \mathrm{O}$ time-series of Chinese peat cellulose, The Holocene, 10, 1-7, 2000.

Jian, Z., Wang, P., Saito, Y., Wang, J., Pflaumann, U., Oba, T., and Cheng, X.: Holocene variability of the Kuroshio current Trough, northwestern Pacific ocean, Earth. Planet. Sci. Lett., 184, 305319, 2000. 
Johnsen, S. J., Clausen, H. B., Dansgaard, W., Gundestrup, N. S., Hammer, C. U., Andersen, U., Andersen, K. K., Hvidberg, C. S., Dahl-Jensen, D., Steffensen, J. P., Shoji, H., Sveinbjörnsdóttir, Á. E., White, J., Jouzel, J., and Fishe, D.: The $\delta^{18} \mathrm{O}$ record along the Greenland Ice Core Project deep ice core and the problem of possible Eemian climatic instability, J. Geophys. Res., 102, 26397-26410, 1997.

Joussaume, S., Taylor, K. E., Braconnot, P., Webb, R. S., and Wyputta, U.: Monsoon changes for 6000 years ago: results of 18 simulations from the Paleoclimate Modeling Intercomparison Project (PMIP), Geophys. Res. Lett., 26, 859-862, 1999.

Keeling, C. D. and Wharf, T. P.: The 1800-year oceanic tidal cycle: a possible cause of rapid climate change, Proc. Natl. Acad. Sci. USA, 97, 3814-3819, 2000.

Kerr, R. A.: A North Atlantic climate pacemaker for the centuries, Science, 288, 1984-1986, 2000.

Knudsen, M. F., Seidenkrantz, M., Jacobsen, B. H., and Kuijpers, A.: Tracking the Atlantic Multidecadal Oscillation through the last 8,000 years, Nat. Commun., 2, 178, doi:10.1038/ncomms1186, 2011.

Kodera, K.: Solar influence on the Indian Ocean monsoon through dynamical processes, Geophys. Res. Lett., 31, L24209, doi:10.1029/2004GL020928, 2004.

Lin, Z. S. and Wang, S. G.: EMD Analysis of Solar Insolation, Meteorol. Atmos. Phys., 93, 1871-1893, 2006.

Lean, J.: Solar forcing of climate change in recent millennia, in: Climate development and history of the North Atlantic realm, edited by: Wefer, G., Berger, W. H., Behre, K.-E., and Jansen, E., Berlin, Springer-Verlag, 75-88, 2002.

Mann, M. E., Cane, M. A., Zebiak, S. E., and Clement, A.: Volcanic and solar forcing of the tropical Pacific over the past 1000 years, J. Climate, 18, 447-456, 2005.

Mazzarella, A. and Scafetta, N.: Evidences for a quasi 60-year North Atlantic Oscillation, Theor. Appl. Climatol., 107, 599609, 2012.

Miller, B. F. and Scott, E. M.: Cosmogenic radiocarbon and cyclical natural processes, Radiocarbon, 37, 417-424, 1995

Minobe, S.: A 50-70 year climatic oscillation over the North Pacific and North America, Geophys. Res. Lett., 24, 683-686, 1997.

Muscheler, R., Joos, F., Beer, J., Müller, S. A., Vonmoos, M., and Snowball, I.: Solar activity during the last 1000 years inferred from radionuclide records, Quaternary Sci. Rev., 26, 8297, 2007.

Naidu, P. D. and Malmgren, B. A.: A 2200-2400 year periodicity in the Asian monsoon system, Geophys. Res. Lett., 22, 2361-2364, 1995

Neff, U., Burns, S. J., Mangini, A., Mudelsee, M., Fleitmann, D., and Matter, A.: Strong coherence between solar variability and the monsoon, Nature, 411, 290-293, 2001.

Ogurtsov, M. G., Nagovitsyn, Y. A., Kocharov, G. E., and Jungner, H.: Long-period cycles of the Sun's activity recorded in direct solar data and proxies, Sol. Phys., 211, 371-394, 2002.

Overpeck, J., Anderson, D. M., Trumbore, S., and Prell, W.: The southwest Indian Monsoon over the last 18,000 years, Clim. Dynam., 12, 213-225, 1996.

Peristykh, A. N. and Damon, P. E.: Persistence of the Gleissberg 88-yr solar cycle over the last 12,000 years: Evidence from cosmogenic isotopes, J. Geophys., 108, 1003, doi:10.1029/2002JA009390, 2003.
Qian, S.: Introduction to Time-Frequency and Wavelet Transforms, Prentice- Hall Inc., Upper Saddle River, NJ, 2002.

Reimer, P. J., Baillie, M. G. L., Bard, E., Bayliss, A., Beck, J. W., Bertrand, C. J. H., Blackwell, P. G., Buck, C. E., Burr, G. S., Cutler, K. B., Damon, P. E., Edwards, R. L., Fairbanks, R. G., Friedrich, M., Guilderson, T. P., Hogg, A. G., Hughen, K. A., Kromer, B., McCormac, G., Manning, S., Ramsey, C. B., Reimer, R. W., Remmele, S., Southon, J. R., Stuiver, M., Talamo, S., Taylor, F. W., van der Plicht, J., and Weyhenmeyer C. E.: IntCal04 terrestrial radiocarbon age calibration, 0-26 cal kyr BP, Radiocarbon, 46, 1029-1058, 2004.

Roth, S. and Reijmer, J. J. G.: Holocene millennial to centennial carbonate cyclicity recorded in slope sediments of the Great Bahama Bank and its climatic implications, Sedimentology, 52, 161-181, 2005.

Rousse, S., Kissel, C., Laj, C., Eiríksson, J., and Knudsen, K. L.: Holocene Centennial to Millennial-scale climatic variability: evidence from high-resolution magnetic analyses of the last 10 cal kyr off North Iceland (core MD99-2275), Earth. Planet. Sci. Lett., 242, 390-405, 2006.

Schlesinger, M. E. and Ramakutty, N.: An oscillation in the global climate system of period 65-70 years, Nature, 367, 723-726, 1994.

Schulz, M. and Mudelsee, M.: REDFIT: Estimating red-noise spectra directly from unevenly spaced paleoclimatic time series, Comput. Geosci., 28, 421-426, 2002.

Sirocko, F., Sarnthein, M., Erlenkeuser, H., Lange, H., Arnold, M., and Duplessy, J. C.: Century-scale events in monsoonal climate over the past 24000 years, Nature, 364, 322-324, 1993.

Stríkis, N. M., Francisco, W., Cruz, F. W., Cheng, H., Karmann, I., Edwards, R. L., Vuille, M., Wang, F., de Paula, M. S., Novello, V. F., and Auler, A. S.: Abrupt variations in South American monsoon rainfall during the Holocene based on a speleothem record from central-eastern Brazil, Geology, 39, 1075-1078, 2011.

Stuiver, M., Reimer, P. J., Bard, E., Warreneck, J., Burr, G. S., Hughen, K. A., Kromer, B., McCormac, G., van der Plicht, J., and Spurk, M.: Intcal98 radiocarbon age calibration, 24000-0 cal BP, Radiocarbon, 40, 1041-1083, 1998.

Stuiver, M. and Braziunas, T. F.: Modeling atmospheric ${ }^{14} \mathrm{C}$ influences and ${ }^{14} \mathrm{C}$ ages of marine samples to $10,000 \mathrm{BC}$, Radiocarbon, 35, 137-189, 1993.

Thamban, M., Kawhata, H., and Rao, V. P.: Indian summer monsoon variability during the Holocene as recorded in sediments of the Arabian Sea: Timing and implications, J. Oceanography, 63, 1009-1020, 2007.

Torrence, C. and Compo, G. P.: A practical guide to wavelet analysis, Bull. Am. Meteorol. Soc., 79, 61-78, 1998.

Usoskin, I. G., Horiuchi, K., Solanki, S., Kovaltsov, G. A., and Bard, E. : On the common solar signal in different cosmogenic isotope data sets, J. Geophys. Res., 114, A03112, doi:10.1029/2008JA013888, 2009.

Vonmoos, M., Beer, J., and Muscheler, R.: Large variations in Holocene solar activity: Constraints from ${ }^{10} \mathrm{Be}$ in the Greenland Ice Core Project ice core, J. Geophys. Res., 111, A10105, doi:10.1029/2005JA011500, 2006.

Wagner, G., Beer, J., Masarik, J., Muscheler, R., Kubik, P., Mende, W., Laj, C., Raisbeck, G. M., and Yiou, F.: Presence of the solar de Vries cycle ( 205 years) during the last ice age, Geophys. Res. Lett., 28, 303-306, 2001. 
Wang, Y., Cheng, H., Edwards, L.R., He, Y., Kong, X., An, Z., Wu, J., Kelly, M. J., Dykoski, C. A., and Li, X.: The Holocene Asian monsoon: links to solar changes and north Atlantic climate, Science, 308, 854-857, 2005.

Weber, S. L., Crowley, T. J., and van der Schrier, G.: Solar irradiance forcing of centennial climate variability during the Holocene, Clim. Dynam., 22, 539-553, 2004.

Witt, A. and Schumann, A. Y.: Holocene climate variability on millennial scales recorded in Greenland ice cores, Nonlin. Processes Geophys., 12, 345-352, 2005,

http://www.nonlin-processes-geophys.net/12/345/2005/.

Wu, Z., Huang, N. E., Long, S. R., and Peng, C. K.: On the trend, detrending, and variability of nonlinear and nonstationary time series, Proc. Natl. Aca. Sci., 104, 14889-14894, 2007.

Xiao, S. B., Li, A. C., Liu, P., Chen, M. H., Xi, Q., Jiang, F., Li, T. G., Xiang, R., and Chen, Z.: Coherence between solar activity and the East Asian winter monsoon variability in the past 8000 years from Yangtze River-derived mud in the East China Sea, Palaeogeogr. Palaeoclimatol., 237, 293-304, 2006.

Xu, H., Hong, Y., Lin, Q., Hong, B., Jiang, H., and Zhu, Y.: Temperature variations in the past 6000 years inferred from $\delta^{18} \mathrm{O}$ of peat cellulose from Hongyuan, China, Chinese Sci. Bull., 47, 15781584, 2002.
Xue, J. and Zhong, W.: Holocene climate variation denoted by Barkol Lake sediments in northeastern Xinjiang and its possible linkage to the high and low latitude climates, Sci. China Ser. D-Earth Sci., 54, 603-614, 2011.

Yiou, F., Raisbeck, G. M., Baumgartner, S., Beer, J., Hammer, C., Johnsen, S., Jouzel, J., Kubik, P. W., Lestringuez, J., Stieveard, M., Suter, M., and Yiou, P.: Beryllium 10 in the Greenland Ice Core Project ice core at Summit, Greenland, J. Geophys. Res., 102, 26783-26794, 1997.

Yin, Z. Q., Ma, L. H., Han, Y., and Han, Y. G.: Long-term variations of solar activity, Chinese. Sci. Bull., 52, 2737-2741, 2007.

Zong, Y., Lloyd, J. M., Leng, M. J., Yim, W. W. S., and Huang, G.: Reconstruction of Holocene monsoon history from the Pearl River Estuary, southern China, using diatoms and carbon isotope ratios, The Holocene, 16, 251-263, 2006.

Zhu, Y., Chen, Y., Zhao, Z., Xiao, J., Zhang, M., and Zhao, H.: Record of environmental change by cellulose $\delta^{13} \mathrm{C}$ of sphagnum peat at Shennongjia, 4000-1000 aBP, Chinese. Sci. Bull., 54, 3731-3738, 2009. 